\title{
A Study on Seed Damage in Plating Electrolyte and Its Repairing in Cu Damascene Metallization
}

\author{
Sung Ki Cho, ${ }^{\text {a,* }}$ Taeho Lim, ${ }^{\text {a,** Hong-Kee Lee, }}{ }^{\text {b }}$ and Jae Jeong Kim ${ }^{\text {a, }, \text {, }}$ \\ ${ }^{a}$ Research Center for Energy Conversion and Storage, School of Chemical and Biological Engineering, \\ Seoul National University, Seoul 151-744, Korea \\ ${ }^{b}$ Incheon Technology Service Division, Korea Institute of Industrial Technology, Incheon 406-840, Korea
}

\begin{abstract}
In this study, we observed the changes in the film properties of a $\mathrm{Cu}$ seed layer with its damage and repair. The immersion of the $\mathrm{Cu}$ seed layer in a sulfuric-acid-based plating electrolyte can result in damage to the $\mathrm{Cu}$ seed layer by the dissolution of the native $\mathrm{Cu}$ oxide and corrosion of $\mathrm{Cu}$, leading to defects in the subsequent electrodeposited layer. The damaged seed layer was repaired using electroless plating. $\mathrm{Cu}$ re-covered the surface and the crystal structure of the seed layer was rebuilt and, finally, the filling characteristic was improved into superfilling in $\mathrm{Cu}$ electroplating for the damascene process. Electroless repairing, however, increased the seed roughness due to the low nucleation on the exposed barrier surface and the accompanying three-dimensional $\mathrm{Cu}$ growth. To refine the repairing process by inducing the nucleation on the barrier surface, $\mathrm{Sn}-\mathrm{Pd}$ activation was adopted before the repair, and it reduced the surface roughness and improved the continuity of the seed layer effectively.

(C) 2010 The Electrochemical Society. [DOI: 10.1149/1.3291985] All rights reserved.
\end{abstract}

Manuscript submitted October 27, 2009; revised manuscript received December 11, 2009. Published February 9, 2010.

$\mathrm{Cu}$ electroplating has been used in the damascene process for forming interconnects in microprocessors, mainly due to the superior capability in filling the recessed region. Generally, it requires a $\mathrm{Cu}$ seed layer, which provides nucleation sites for the formation of a continuous film. ${ }^{1,2}$ Additionally, it reduces the potential drop originating from its own resistance and, accordingly, prevents a higher deposition rate on the substrate near the points electrically connected to the electron supplier for electroplating. ${ }^{3,4}$ Moreover, the nature of the seed layer affects the resistivity, crystallinity, and adhesion of the electrodeposit. ${ }^{5-8}$

In submicrometer technology generations, the $\mathrm{Cu}$ seed layer is usually deposited using a physical vapor deposition (PVD) method. As the trench width decreases to the tens of nanometers range, it becomes more difficult to obtain a continuous and conformal seed layer on the trench wall, especially at the trench base. This is due to the directional deposition of PVD, which results in a "bottom void" during trench filling. ${ }^{4}$ Moreover, the coverage of the seed layer becomes worse by the damage in the acidic plating electrolyte. The native $\mathrm{Cu}$ oxide formed on the seed layer is dissolved in the acidic electrolyte, resulting in defects in the seed layer. ${ }^{4,8-10}$ Martyak and Ricou $^{2}$ observed seed layer damage in a sulfuric-acid-based electrolyte by applying $100 \mu \mathrm{A} / \mathrm{cm}^{2}$ of anodic current on the seed layer.

Before adopting methods such as atomic layer deposition and electroless plating in the seed layer fabrication, seed layer repair has been suggested as a bridge between PVD and the methods mentioned. Seed layer repair is a technique that improves the continuity of the seed layer by connecting sparse parts of $\mathrm{Cu}$ seed through the addition of a few $\mathrm{Cu}$ layers. Electroless plating, ${ }^{11}$ alkaline-based electroplating, ${ }^{11,12}$ and low acid electroplating ${ }^{10}$ have been reported as repairing methods.

This work is a fundamental study on the seed damage and its repair using electroless plating for the appropriate application of repairing in the damascene process. We caused damage to a seed layer via immersion in an acidic plating electrolyte and repaired it using electroless plating, and we observed changes in the properties of the seed layer and the effect on the subsequent electroplating for each treatment.

\section{Experimental}

$\mathrm{Cu}$ seed layers used in this study were 10,30 , and $50 \mathrm{~nm}$ thick and were formed on a nonpatterned $\mathrm{Si}$ wafer, which has the multilayers of PVD Ta $(7.5 \mathrm{~nm}) / \mathrm{PVD}$ TaN $(7.5 \mathrm{~nm})$. A patterned wafer, which has $55 \mathrm{~nm}$ width trenches with an aspect ratio of 3.5 and PVD

\footnotetext{
* Electrochemical Society Active Member.

** Electrochemical Society Student Member.

z E-mail: jikimm@snu.ac.kr
}

$\mathrm{Cu}(7.5 \mathrm{~nm}) / \mathrm{PVD} \mathrm{Ta}(6 \mathrm{~nm}) / \mathrm{PVD}$ TaN $(1.5 \mathrm{~nm}) / \mathrm{Si}$ multilayer, was also used in the trench-filling experiment. The wafer was dipped in a conventional sulfuric-acid-based solution for $300 \mathrm{~s}$ as a damaging process. The composition of the plating solution was $\mathrm{CuSO}_{4} \cdot 5 \mathrm{H}_{2} \mathrm{O}$ $(0.25 \mathrm{M}), \mathrm{H}_{2} \mathrm{SO}_{4}(1.0 \mathrm{M}), \mathrm{NaCl}(1 \mathrm{mM})$, poly(ethylene glycol) (PEG, $88 \mu \mathrm{M}, \mathrm{Mw} 3400$, Aldrich), and bis(3-sulfopropyl) disulfide (SPS, $50 \mu \mathrm{M}$, Raschig GmbH). 1,2,3-Benzotriazole (BTA, $1 \mathrm{mM}$, Junsei) was added as a corrosion inhibitor. With $99.9 \% \mathrm{Cu}$ wire and a saturated calomel electrode (SCE) as a counter electrode and a reference electrode, respectively, electroplating was performed at $-200 \mathrm{mV}$ (vs SCE) on a $1 \mathrm{~cm}^{2}$ seed layer surface in the plating solution.

The damaged seed layer was repaired using $\mathrm{Cu}$ electroless plating, which was performed at $70^{\circ} \mathrm{C}$ in a solution containing $\mathrm{CuSO}_{4} \cdot 5 \mathrm{H}_{2} \mathrm{O}(0.006 \mathrm{M})$, ethylenediaminetetraacetic acid $(0.0077$ $\mathrm{M})$, paraformaldehyde $\left[(\mathrm{HCHO})_{n}, 0.014 \mathrm{M}\right]$, and $\mathrm{KOH}(0.069 \mathrm{M})$. Surface activation was attempted before electroless plating for the improvement of repairing results. Surface activation was carried out via $\mathrm{Sn}$ sensitization (in $0.03 \mathrm{M} \mathrm{SnCl}_{2}$ and $1.94 \mathrm{M} \mathrm{HCl}$ solution for $120 \mathrm{~s}$ ) and $\mathrm{Pd}$ activation (in $0.56 \mathrm{mM} \mathrm{PdCl}_{2}$ and $0.08 \mathrm{M} \mathrm{HCl}$ solution for $20 \mathrm{~s}$ ) as used for electroless plating on the Ta substrate. ${ }^{13-15}$

Four-point probe analysis (Chang Min Co., CMT-SR 1000N), a field-emission-scanning electron microscope (FESEM, JEOL, JSM6330F), an X-ray photoelectron spectroscope (XPS, Kratos, AXIS), an X-ray diffractometer (XRD, Bruker, D8 Advance), and an atomic force microscope (AFM, Park SYSTEMS, XE-150) were used to analyze the change in the seed properties during the damage and the repair.

\section{Results and Discussion}

Figure 1 shows the changes in the surface morphology and the sheet resistance of the $10 \mathrm{~nm}$ thick seed layer during immersion in the plating electrolyte. It showed that the seed layer was severely damaged by the plating electrolyte, and the underlying barrier layer was exposed to the surface. The sharp increase in the sheet resistance after $200 \mathrm{~s}$ indicates that the seed layer became physically discontinuous. It is easily considered that the damage is caused by the dissolution of the native $\mathrm{Cu}$ oxide on the seed layer, as shown in the following reaction ${ }^{4,9}$

$$
\mathrm{CuO}+2 \mathrm{H}^{+} \rightarrow \mathrm{Cu}^{2+}+\mathrm{H}_{2} \mathrm{O}
$$

The $\mathrm{pH}$ at equilibrium of Eq. 1 is 4.83 (which can be calculated using standard molar Gibbs free energy of formation at $\left[\mathrm{Cu}^{2+}\right]$ $=0.25 \mathrm{M}, 25^{\circ} \mathrm{C}$ ). Because the $\mathrm{pH}$ of the plating electrolyte is 0.24 , this is a thermodynamically spontaneous reaction. The change in the $\mathrm{Cu}$ surface resulted in defects at the surface and increased the sheet resistance of the seed layer. However, the dissolution of thenative oxide is unlikely to be the only one contributing to damage because 

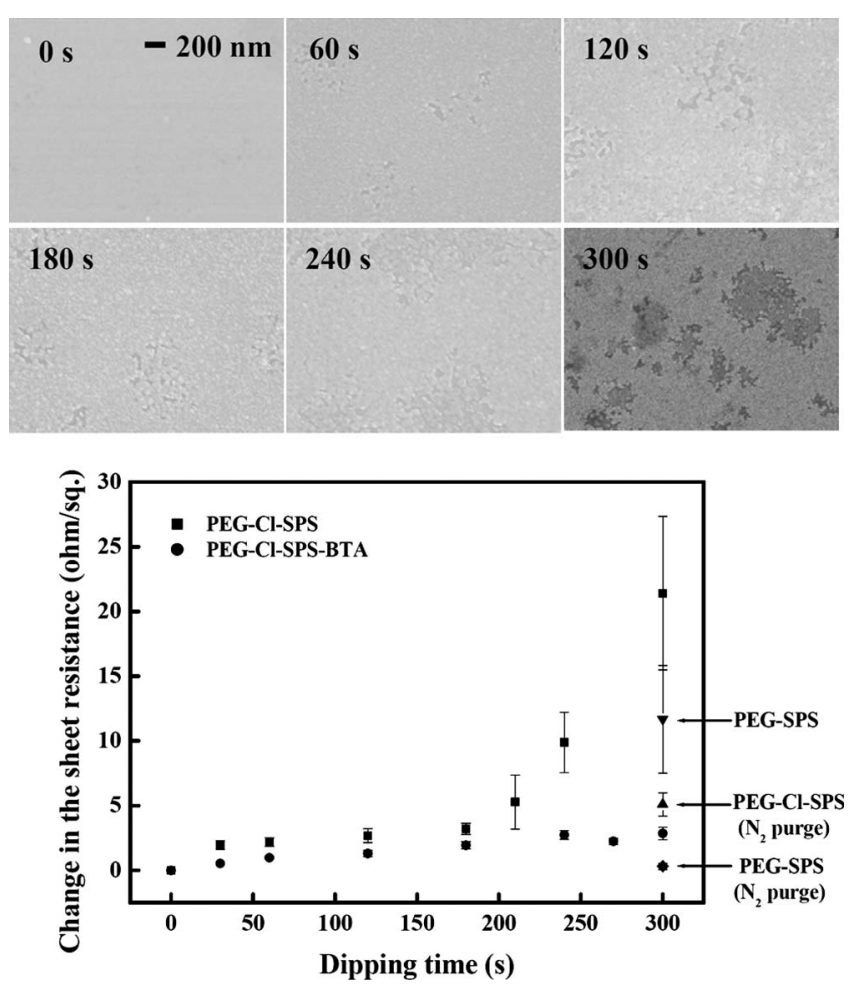

Figure 1. The changes in the surface morphology and the sheet resistance of $10 \mathrm{~nm}$ thick seed layer according to the immersion time in the plating electrolyte.

the native oxide formed on a $10 \mathrm{~nm}$ thick $\mathrm{Cu}$ seed layer was decomposed in a few tens of seconds in the acid solution. ${ }^{16}$ Thus, if the damage were only due to the dissolution of the native oxide, deterioration would not continuously occur for $300 \mathrm{~s}$. Moreover, the thickness of the native oxide layer has been reported to be normally less than $5 \mathrm{~nm}$ with the nonuniform nature, depending on the ambi- ent oxidation condition such as relative humidity, temperature, and the oxidation time. ${ }^{17,18}$ Therefore, dissolution of the native oxide may not be sufficient to expose the underlying layer. Some studies reported that metallic $\mathrm{Cu}$ can be dissolved by corrosion in the sulfuric acid containing oxidants such as Fe salt, dichromate, and dissolved $\mathrm{O}_{2} \cdot{ }^{19-21}$ When BTA was added to the plating electrolyte to inhibit corrosion, the increase in the sheet resistance was almost completely suppressed over all dipping times. The small increase is certainly related to the dissolution of $\mathrm{Cu}$ oxide in the acidic solution. This indicates that the serious damage was mainly due to corrosion induced by oxidants, which damaged the seed layer as the immersion time increased. In this case, the oxidants in the plating electrolyte would be $\mathrm{O}_{2}$ (which was dissolved in contact with air) and $\mathrm{Cl}$ ion (which was added as $\mathrm{NaCl}$ ). To evaluate the effect of dissolved $\mathrm{O}_{2}, \mathrm{~N}_{2}$ purging was conducted to remove dissolved $\mathrm{O}_{2}$ before the seed layer was dipped in the electrolyte. In the purging, 99.9\% $\mathrm{N}_{2}$ gas was flowed in the electrolyte through a $0.5 \mathrm{~cm}$ diameter silicon tube with a flow rate of $100 \mathrm{~mL} / \mathrm{s}$. As shown in Fig. 1, when the plating electrolyte was purged with $\mathrm{N}_{2}$ gas, the sheet resistance did not increase as much as the previous result. Similarly, the absence of $\mathrm{Cl}$ ions in the plating electrolyte also lessened the increase of the sheet resistance related to the damage. $\mathrm{N}_{2}$-purged $\mathrm{Cl}$-absent plating electrolyte as a combinational treatment made a very small increment as much as the BTA-containing electrolyte did. The corrosion caused by dissolved $\mathrm{O}_{2}$ and $\mathrm{Cl}$ ion can be expressed as follows ${ }^{21-23}$

$$
\begin{gathered}
2 \mathrm{Cu}+4 \mathrm{H}^{+}+\mathrm{O}_{2} \rightarrow 2 \mathrm{Cu}^{2+}+2 \mathrm{H}_{2} \mathrm{O} \\
\mathrm{Cu}+2 \mathrm{Cl}^{-} \rightarrow \mathrm{CuCl}_{2}^{-}+\mathrm{e}^{-}
\end{gathered}
$$

In summary, damage to the seed layer by the plating electrolyte occurs in two ways: the dissolution of native $\mathrm{Cu}$ oxide and corrosion caused by dissolved $\mathrm{O}_{2}$ and $\mathrm{Cl}$ ion. The corrosion caused the damage to be more severe compared to the dissolution of the native oxide.

The changes in the composition and crystallinity of the seed layer due to the damage were observed using XPS and XRD analyses, as shown in Fig. 2. Before the immersion in the electrolyte, the XPS peaks of $\mathrm{Cu}(\mathrm{II})$ and the satellite corresponding to the native
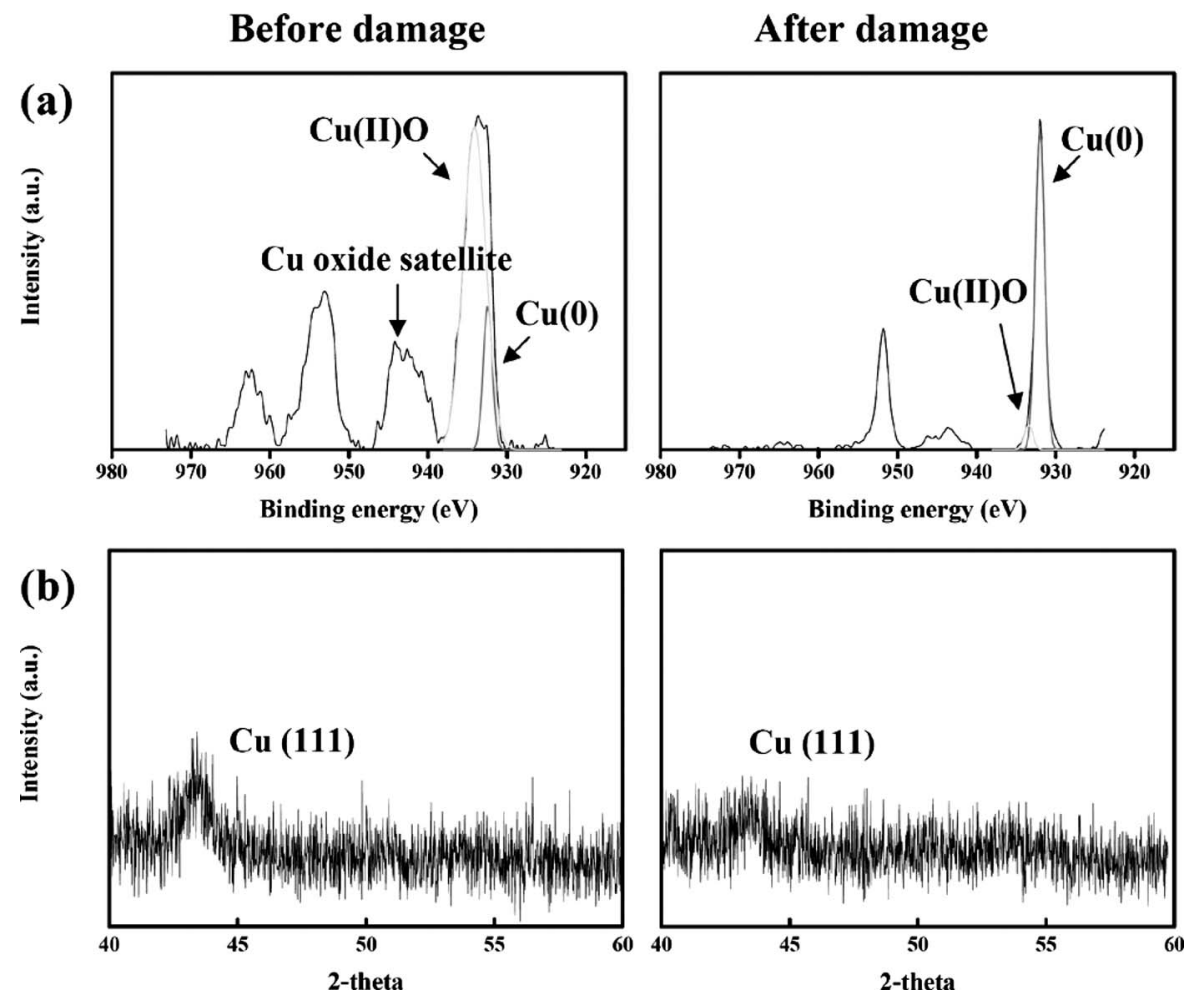

Figure 2. (a) $\mathrm{Cu} 2 \mathrm{p} 3 / 2 \mathrm{X}$-ray photoelectron spectrum and (b) X-ray diffraction spectra of $10 \mathrm{~nm}$ thick seed layer before and after immersion in the plating electrolyte. 


\section{Cu seed layer Electrodeposit}
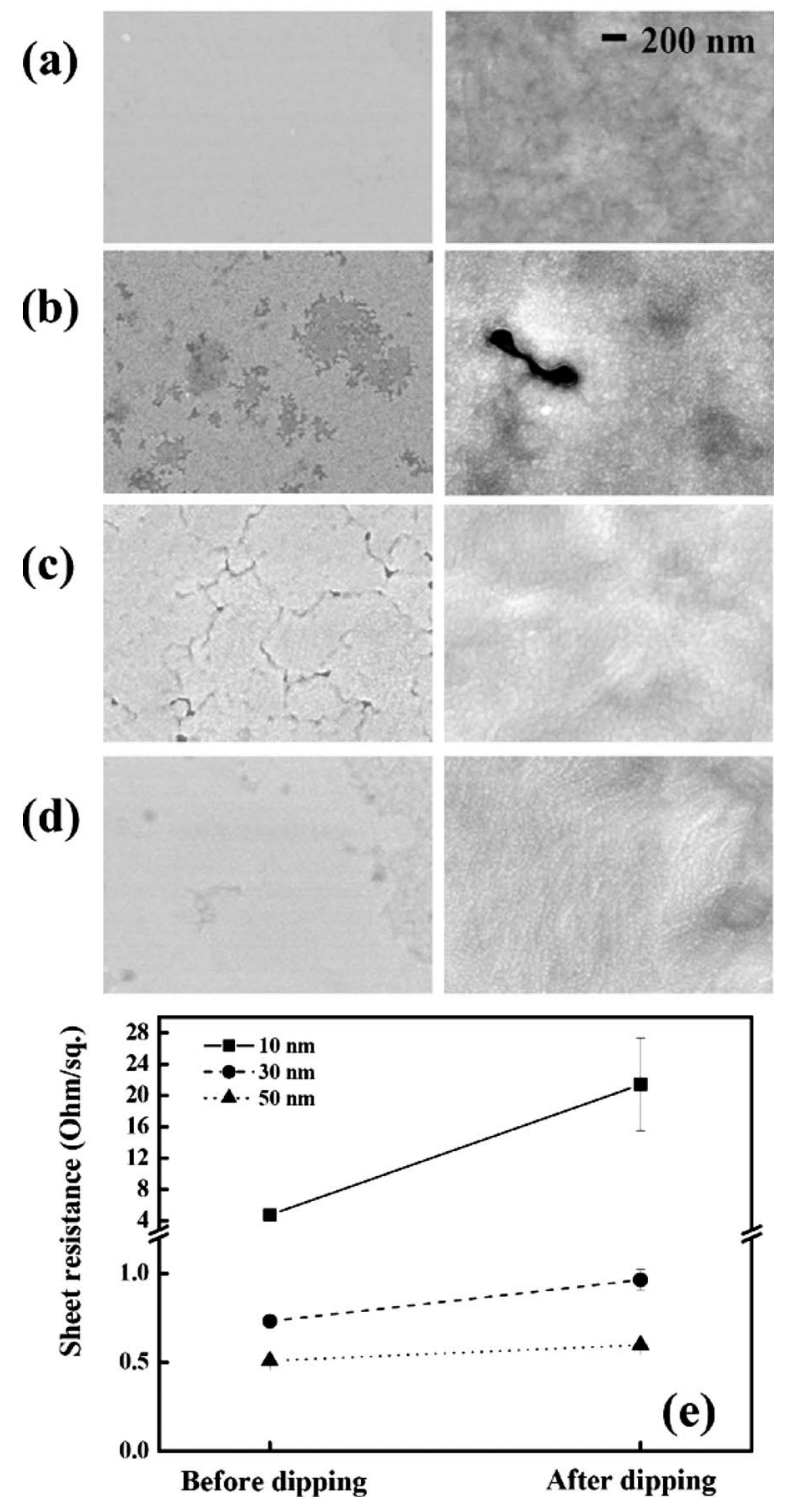

Figure 3. The relationship between the surface damage and the generation of defects in the electrodeposit according to the seed thickness: (a) As-prepared $10 \mathrm{~nm}$ thick seed, (b) damaged $10 \mathrm{~nm}$ thick seed, (c) damaged $30 \mathrm{~nm}$ thick seed, (d) damaged $50 \mathrm{~nm}$ thick seed, and (e) the change in the sheet resistance of the seed layer of various thicknesses with the damage. Electroplating was performed at $-200 \mathrm{mV}$ (vs SCE) for $30 \mathrm{~s}$.

oxide were observed (Fig. 2a). These became smaller after the immersion, which indicates the dissolution of the native oxide. The damage also changed the crystallinity of the seed layer. Figure $2 \mathrm{~b}$ shows XRD spectra of the $10 \mathrm{~nm}$ thick $\mathrm{Cu}$ seed layer before and after the immersion in the electrolyte. Although the spectra show high levels of noise due to the thin seed layer, a (111) preferential orientation was detected on the seed layer. The intensity of the $\mathrm{Cu}(111)$ peak, however, was reduced after immersion in the plating electrolyte due to the dissolution of $\mathrm{Cu}$ accompanying the decrease in the thickness and the destruction of the crystal structure of the seed layer with the corrosion.

Figure 3 shows the surface damage and its effects on the subsequent electroplating with various seed thicknesses. Although a continuous electrodeposit film was obtained from the undamaged $10 \mathrm{~nm}$ thick seed layer (Fig. 3a), defects were visible in the electrodeposit on the damaged seed layer (Fig. 3b). As it is difficult for $\mathrm{Cu}$ to
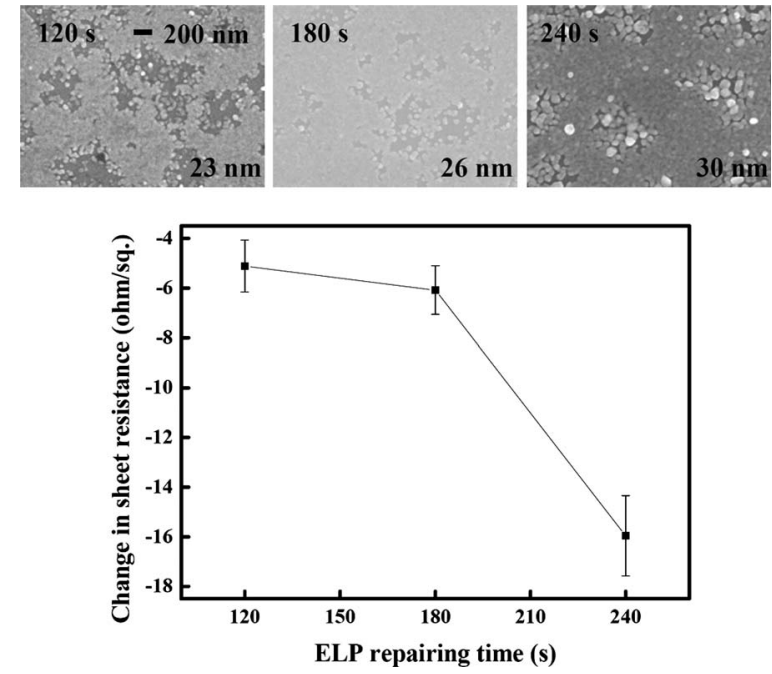

Figure 4. The changes in the surface morphology and the sheet resistance of $10 \mathrm{~nm}$ thick seed layer during seed layer repairing. The number at the bottom of each SEM image corresponds to seed thickness obtained from evaluating the step height in the line scan of AFM analysis.

nucleate on the barrier layer exposed on the surface (due to the damage), uneven and sparse nuclei initially formed and, consequently, $\mathrm{Cu}$ growth progressed three-dimensionally, whereby $\mathrm{Cu}$ electrodeposit had a rough surface and many defects. Thicker seed layers were also damaged by the plating electrolyte, but the degree of damage was less severe than that of the $10 \mathrm{~nm}$ thick seed layer (Fig. 3c and d). As the seed layer became thicker, the sheet resistance increase associated with the damage became smaller (Fig. 3e). In consequence, defects were not generated after the plating on the seed layers with a thickness of over $30 \mathrm{~nm}$. Conclusively, the damage to the seed layer caused to generate defects in the electroplating, and its effect, became serious as the seed layer became thinner in consistency with the shrinkage in the interconnect size.

The damaged seed layer was repaired using electroless plating. Figure 4 shows changes in the sheet resistance and the surface morphology of the $10 \mathrm{~nm}$ thick seed layer with the repair. During repair, the resistivity decreased sharply as the surface was re-covered with $\mathrm{Cu}$, and the seed layer became continuous again. With $240 \mathrm{~s}$ of electroless plating, the sheet resistance reverted almost to the same value as that of the undamaged seed layer, and the surface was almost recovered. Figure 5 shows the reconstruction of the $\mathrm{Cu}(111)$ peak in the XRD analysis after the repair for $120 \mathrm{~s}$. That is, the intensity of the $\mathrm{Cu}(111)$ peak decreased after damage and recovered after the repair, but the crystal orientation of the $\mathrm{Cu}$ seed layer remained unchanged.

Seed repairing was applied to a $55 \mathrm{~nm}$ width trench (Fig. 6). As shown in Fig. 6a and b, the seed layer was readily damaged by the plating electrolyte, whereby $\mathrm{Cu}$ did not superfill the trench (Fig. 6c). In contrast, when the electroless repairing was performed (for $60 \mathrm{~s}$ ) before the immersion in the plating electrolyte, superfilling was successfully achieved in the trench (Fig. 6d).

In summary, seed layer repairing improves the continuity and crystallinity of the seed layer and the filling quality in the subsequent electroplating. However, it resulted in some roughening of the seed layer, as revealed by AFM analyses (Fig. 7). Before applying repair, the damaged recessed regions were found in AFM analyses as well as in FESEM analyses, and its depth was about $10 \mathrm{~nm}$, equal to the total thickness of the seed layer, as shown in an AFM line scan (Fig. 7a). As the repair was performed on the damaged seed layer, the roughness increased to about $13 \mathrm{~nm}$. This is due to the lack of $\mathrm{Cu}$ nucleation on the exposed barrier (Ta) surface. Therefore, $\mathrm{Cu}$ grew three-dimensionally only on the residual $\mathrm{Cu}$ surface (Fig. $7 \mathrm{~b}$ and c). Three-dimensionally grown $\mathrm{Cu}$ regions appeared as domi- 


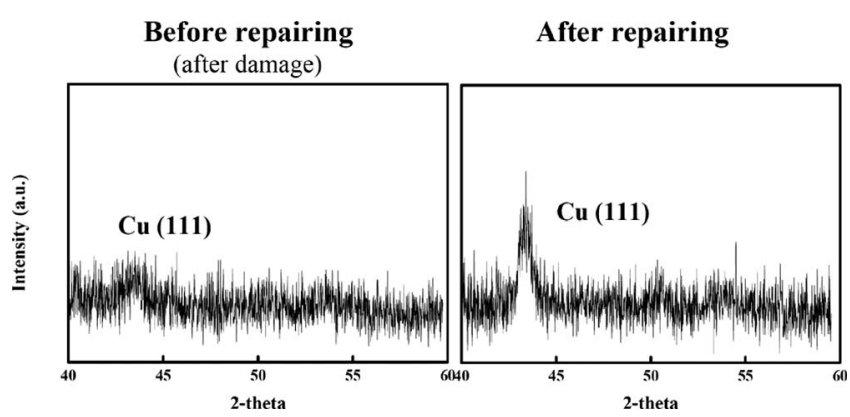

Figure 5. X-ray diffraction spectra of $10 \mathrm{~nm}$ thick $\mathrm{Cu}$ seed layer (a) before and (b) after seed layer repairing (for $120 \mathrm{~s}$ ).

nant peaks in the AFM line scan and as white dots in the SEM image. These indicated that the recovery of the seed coverage was obtained by a three-dimensional and lateral growth of $\mathrm{Cu}$ at the boundary of the recessed region, whereby the roughness and thickness of the seed layer increased. Preferential growth of $\mathrm{Cu}$ at the boundary was shown as a bulge at the end of the recess in the AFM line scan. When the surface was almost completely covered with $\mathrm{Cu}$ after $240 \mathrm{~s}$, the seed layer thickness increased to about $30 \mathrm{~nm}$, which was deduced from evaluating the step height in the line scan.

As a feature of the dimension scale, a thin, continuous, and smooth seed layer becomes central to void-free gap filling. Therefore, the thickness and roughness of the seed layer should be maintained at a minimal value. In this sense, seed layer repairing should be allowed until the seed layer became continuous and, ideally, should be carried out in such a way that $\mathrm{Cu}$ is nucleated on the barrier surface and grows two-dimensionally to minimize roughening. To achieve the nucleation on the barrier layer and twodimensional $\mathrm{Cu}$ growth, $\mathrm{Sn}-\mathrm{Pd}$ activation was performed on the damaged seed layer. Sn-Pd activation is a surface treatment method used in $\mathrm{Cu}$ electroless plating to deposit $\mathrm{Cu}$ on $\mathrm{Ta}$ and $\mathrm{TaN}$ surfaces. ${ }^{13-15}$ Figure 8 shows schematic diagrams of the repair process with and without the surface activation. When electroless repairing is performed on the damaged surface, $\mathrm{Cu}$ grows only where $\mathrm{Cu}$ already exists, resulting in the rough seed layer with incomplete (a) As-prepared seed

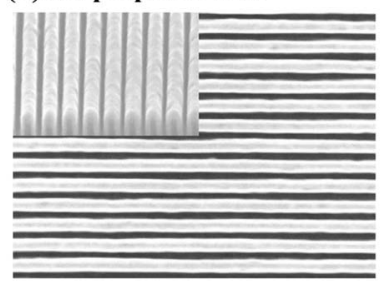

(b) Damaged seed

(c) EP on the as-prepared seed (d) EP on the repaired seed
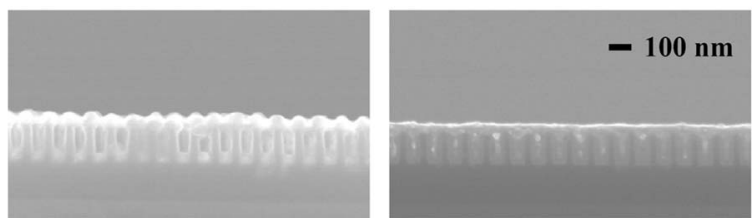

Figure 6. FESEM images of the seed layers, which were (a) as-prepared and (b) damaged, and electrodeposits on the seed layers which were (c) not repaired and (d) repaired (for $60 \mathrm{~s}$ ) in the $55 \mathrm{~nm}$ trench. Electroplating was performed at $-200 \mathrm{mV}$ for $6 \mathrm{~s}$ with PEG-Cl-SPS additives.

$\mathrm{Cu}$ coverage. However, when surface activation is performed before electroless repairing, the $\mathrm{Sn}-\mathrm{Pd}$ catalyst is formed on the barrier surface and allows nucleation of $\mathrm{Cu}$ as well as on $\mathrm{Cu}$ surfaces, resulting in a more continuous seed layer with less roughness.

Figure 9 shows FESEM and AFM images of the repaired seed layer using the surface activation as a pretreatment. The SEM image in Fig. 9a shows that the Sn-Pd particles were formed on the barrier surface, as observed in the AFM image. When electroless repairing was performed on the Sn-Pd particle-populated surface, it covered the surface with $\mathrm{Cu}$ perfectly even in just $30 \mathrm{~s}$, with a low surface roughness of about $7 \mathrm{~nm}$. This is a reduction of $40 \%$ in roughness compared to that of the repaired seed without activation (Fig. 9b-d). The rapid repairing using Sn-Pd activation was also adopted in trench filling (Fig. 10). As shown in Fig. 10a, repairing without $\mathrm{Sn}-\mathrm{Pd}$ activation for $30 \mathrm{~s}$ was insufficient to guarantee superfilling in the subsequent electroplating. However, when activation was per-

\section{(a) After damage (rms: $2.9 \mathrm{~nm})$}
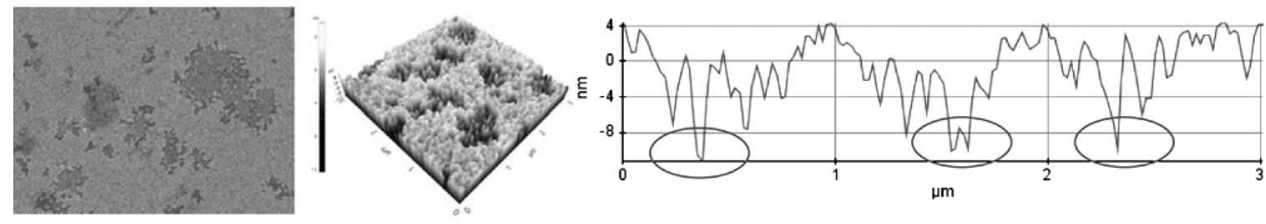

\section{(b) After repairing (120 s, rms: $12.0 \mathrm{~nm})$}
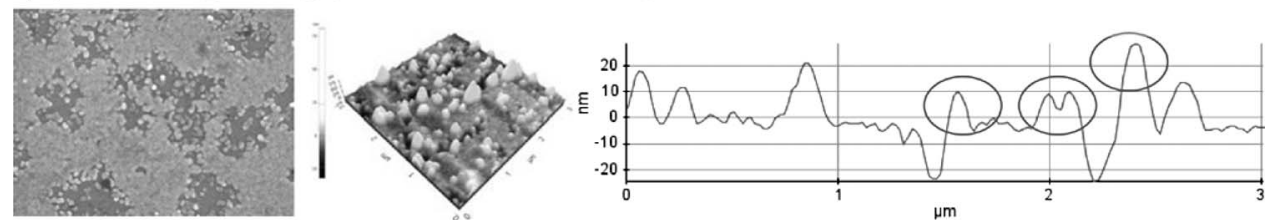

Figure 7. Surface images of FESEM analyses, and surface images and line-scan profiles of AFM analyses on the seed layers which were (a) damaged and [(b) and (c)] electrolessly repaired [for (b) 120 and (c) $240 \mathrm{~s}$, respectively].

\section{(c) After repairing (240 s, rms: $13.3 \mathrm{~nm})$}
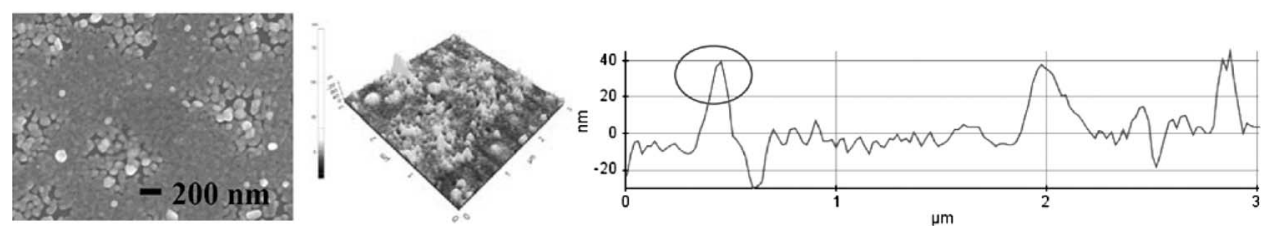
(a) Repairing without activation

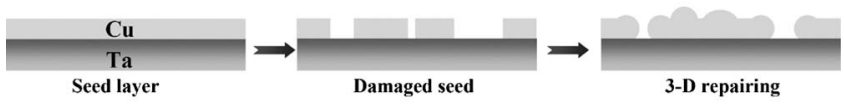

(b) Repairing with activation

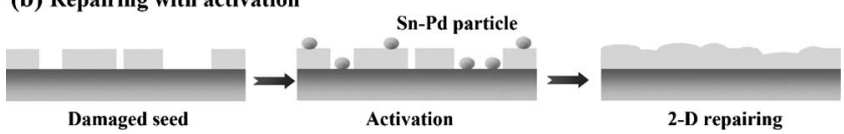

Figure 8. Schematic diagrams of repairing process of the seed layer using electroless plating (a) without and (b) with $\mathrm{Sn}-\mathrm{Pd}$ surface activation.

\section{(a) EP on the seed repaired without activation}

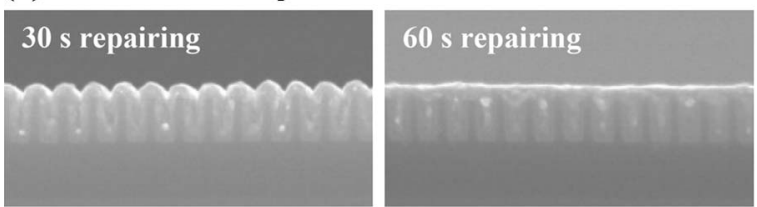

(b) EP on the seed repaired with activation

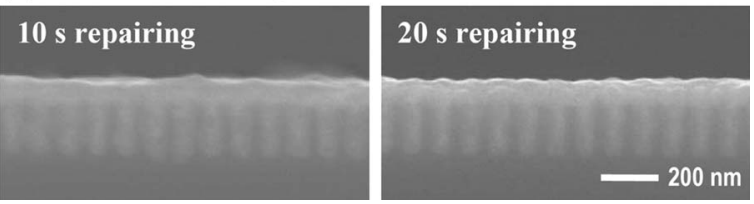

Figure 10. FESEM images of $\mathrm{Cu}$ electrodeposits on the seed layers which were repaired (a) without and (b) with Sn-Pd activation. Electroplating was performed at $-200 \mathrm{mV}$ for $6 \mathrm{~s}$ with PEG-Cl-SPS additives.

\section{Conclusions}

Damage to the $\mathrm{Cu}$ seed layer occurred due to the acidic plating electrolyte. This was associated with the dissolution of native $\mathrm{Cu}$ oxide and corrosion of $\mathrm{Cu}$ with the dissolved $\mathrm{O}_{2}$ and $\mathrm{Cl}$ ions in the plating electrolyte. It increased the resistance and decreased the (111) crystallinity of the seed layer and defects in the electrodeposit. The damaged seed layer was repaired using electroless plating, and the original resistance and crystallinity were obtained. However, the roughness of the seed layer increased because of the threedimensional growth of $\mathrm{Cu}$, originating from the absence of nucleation on the barrier surface. This was remedied by applying a Sn-Pd activation. Sn-Pd activation before electroless repairing, which allowed $\mathrm{Cu}$ to nucleate on the barrier layer, resulted in a more rapid repair with reduced surface roughness. Because seed layer repairing is a supplemental method, it can be applied as long as it does not seriously change the properties of the seed layer.

\section{Acknowledgments}

(b) Repairing with activation (30 s, rms: $7.5 \mathrm{~nm}$ )
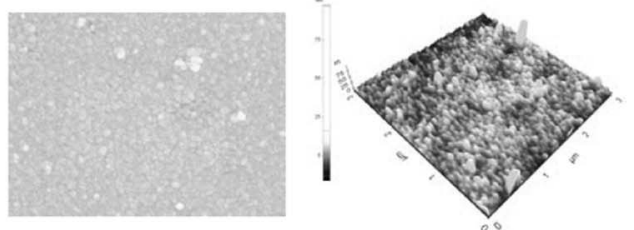

(c) Repairing with activation (60 s, rms: $8.4 \mathrm{~nm}$ )
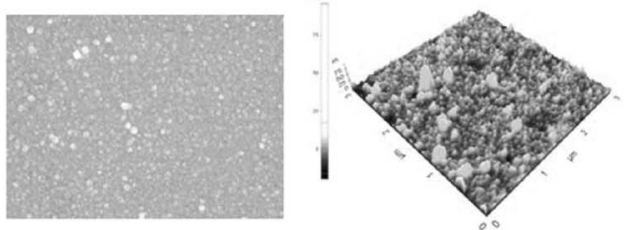

(d) Repairing with activation (90 s, rms: $6.8 \mathrm{~nm})$
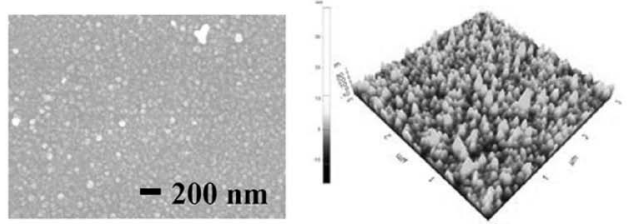

Figure 9. Surface images of FESEM and AFM analyses on the seed layers which were (a) activated and [(b)-(d)] electrolessly repaired [for (b) 30, (c) 60, and (d) $90 \mathrm{~s}$, respectively] after Sn-Pd activation.
This work was supported by the Korea Science and Engineering Foundation (KOSEF) through the Research Center for Energy Conversion and Storage (RCECS) and through the Nano R\&D program funded by the Ministry of Education, Science and Technology (2009-0083223). It was also supported by a grant from the Fundamental R\&D Program for Core Technology of Materials funded by the Ministry of Commerce, Industry and Energy, Republic of Korea.

Seoul National University assisted in meeting the publication costs of this article.

\section{References}

1. P. M. Hoffmann, A. Radisic, and P. C. Searson, J. Electrochem. Soc., 147, 2576 (2000).

2. N. M. Martyak and P. Ricou, Mater. Sci. Semicond. Process., 6, 225 (2003).

3. K. M. Takahashi, J. Electrochem. Soc., 147, 1414 (2000).

4. J. Reid, Jpn. J. Appl. Phys., Part 1, 40, 2650 (2001).

5. K. Weiss, S. Riedel, S. E. Schulz, M. Schwerd, H. Helneder, H. Wendt, and T. Gessner, Microelectron. Eng., 50, 433 (2000).

6. J. J. Kim, S.-K. Kim, C. H. Lee, and Y. S. Kim, J. Vac. Sci. Technol. B, 21, 33 (2003).

7. T. Hara and H. Toida, Electrochem. Solid-State Lett., 5, C102 (2002).

8. N. M. Martyak and P. Ricou, Mater. Chem. Phys., 84, 87 (2004).

9. J. Reid, S. Mayer, E. Broadbent, E. Klawuhn, and K. Ashtiani, Solid State Technol., 43, 86 (2000)

10. R. A. Mikkola and J. M. Calvert, U.S. Pat. 6,682,642 (2004).

11. T. Andryuschenko and J. Reid, in IEEE International Interconnect Conference 2001, IEEE, p. 33 (2001).

12. S.-W. Lee, F. G. Shi, and S. D. Lopatin, Microelectron. J., 33, 945 (2002).

13. C. H. Lee, S. H. Cha, A. R. Kim, J.-H. Hong, and J. J. Kim, J. Electrochem. Soc., 154, D182 (2007).

14. S.-Y. Chang, C.-J. Hsu, R.-H. Fang, and S.-J. Lin, J. Electrochem. Soc., 150, C603 (2003).

15. H.-H. Hsu, C.-W. Teng, S.-J. Lin, and J.-W. Yeh, J. Electrochem. Soc., 149, C143 (2002). 
16. H. Majima, Y. Awakura, T. Yazaki, and Y. Chikamori, Metall. Trans. B, 11, 209 (1980).

17. S. Suzuki, Y. Ishikawa, M. Isshiki, and Y. Waseda, Mater. Trans., JIM, 38, 1004 (1997).

18. J. J. Kim and S.-K. Kim, Appl. Surf. Sci., 183, 311 (2001).

19. C. V. King and L. Weidenhammer, J. Am. Chem. Soc., 58, 602 (1936).
20. D. P. Gregory and A. C. Riddiford, J. Electrochem. Soc., 107, 950, and references therein (1960).

21. S. M. Mayanna and T. H. V. Setty, Corros. Sci., 15, 627 (1975).

22. S. M. Mayanna and T. H. V. Setty, Proc. Indian Acad. Sci., Math. Sci. 80, 184 (1974).

23. A. Shaban, E. Kálmán, and J. Telegdi, Electrochim. Acta, 43, 159 (1998). 